\title{
School bullying as a collective action: Stigma processes and identity struggling
}

\author{
Robert Thornberg \\ Linköping University Post Print
}

Tweet

N.B.: When citing this work, cite the original article.

Original Publication:

Robert Thornberg, School bullying as a collective action: Stigma processes and identity struggling, 2015, Children \& society, (29), 4, 310-320.

http://dx.doi.org/10.1111/chso.12058

Copyright: 2013 Wiley: 24 months

http://eu.wiley.com/WileyCDA/

Postprint available at: Linköping University Electronic Press

http://urn.kb.se/resolve?urn=urn:nbn:se:liu:diva-105639 


\title{
School Bullying as a Collective Action: Stigma Processes and Identity Struggling
}

\author{
Robert Thornberg \\ Department of Behavioural Sciences and Learning, \\ Linköping University, Linköping, Sweden
}

\begin{abstract}
The aim of this study was to investigate the collective action of bullying and its stigma processes and influences on identities. In accordance with interactionism, identity is a social process, constructed and reconstructed in everyday social interactions. Ethnographic fieldwork was conducted in four school classes, investigating six bullying cases. Grounded theory methods were used to explore and analyse data. Co-constructing differentness was found to be a core process in bullying. Bullying often appeared to function like a self-serving and socially inclusive ritual in which the bullies co-constructed the 'normal us'. Loss of belonging, self-deprecation and identity struggling followed closely upon the sense of becoming socially discredited. Victims were trapped in the collective action. The findings highlight the significance of addressing peer cultures and the social psychology of everyday school life in anti-bullying policies and practices.
\end{abstract}

Keywords: blaming the victim, bullying, dehumanisation, grounded theory, identity, labelling, social interaction, stigma.

\section{Introduction}

Bullying can be defined as a social process in which a child in a less powerful position is repeatedly harassed or excluded by others (Salmivalli, 2010). Children \& Society published a special issue on bullying 2011 (Vol. 25 , Issue 4) in which alternative research approaches to bullying were represented. In tune with that special issue, in this study I have used a sociological approach to address and investigate bullying. According to interactionism (Atkinson and Housley, 2003; Blumer, 1969; Charon, 2007), social life and morality are inescapably social, collective and cultural processes constructed and reconstructed in everyday social interactions and by individuals' interpretation processes. Shared meanings of what is expected in the actions of participants guide people's behaviour. With reference to the new sociology of childhood (Corsaro, 2005; Prout and James, 1997; Wyness, 2006), children co-construct and participate in their own peer cultures by creatively appropriating and reconstructing information and norms from the adult world to address their own concerns (Corsaro, 2005; Wyness, 2006). Identity is a social process, not a fixed entity, constructed and reconstructed in interpersonal negotiations and interactions. People see and judge themselves from the standpoints of their groups and by inter- 
preting others' reactions upon their actions. The collective processes and discourses of normative orders and social categories construct or undermine social actors' identities (Atkinson and Housley, 2003; Blumer, 1969; Charon, 2007).

Previous research has indicated that in bullying processes and peer discourses, victims tend to be socially constructed as odd, different, deviant or people who do not 'fit in' (Bibou-Nakou and others, 2012; Frisén and others, 2008; Hamarus and Kaikkonen, 2008; Teräsahjo and Salmivalli, 2003; Thornberg, 2010; Thornberg and Knutsen, 2011; Thornberg and others, 2013; Varjas and others, 2008). The constructed 'differentness' or 'deviance' is then used to justify bullying (Lahelma, 2004; Teräsahjo and Salmivalli, 2003; Thornberg, 2010). For instance, Evaldsson and Svahn (2012) found how girls who were reported as bullies justified their actions as ordinary and rational, and labelled the targeted peer as 'a liar', 'whore' and 'fucking abnormal'. Such meaningmaking and interaction patterns can be understood as stigma (Goffman, 1963) and labelling processes (Becker, 1963; Phelan and Link, 1999). According to Phelan and Link (1999, p. 140), a label is a definition, and 'when applied to a person, it identifies or defines what type of a person he or she is'. A label can be either 'deviant' or 'normal'. When individuals are labelled as deviant, they are defined as people who violate important social taken-for-granted norms of the social group, culture or society. Phelan and Link (1999) argue that stigma is the core concept of understanding the consequences of labelling.

Qualitative studies on bullying have shown that being negatively labelled as different becomes the dominant feature of the victim's social identity at school (Cadigan, 2002; Dixon and others, 2004; Kinney, 1993; Kless, 1992; Merton, 1996; Thornberg and others, 2013). A negative reputation of the victim is constructed and spread further within the community. Even those who do not actively participate in bullying do not want to socialise with the victim because of social pressure (Hamarus and Kaikkonen, 2008). Once being constructed as a victim, stigmatised with negative labels and rejected by peers, ethnographic findings revealed that it was almost impossible for these students to change their status and improve their situation (Cadigan, 2002; Evans and Eder, 1993; Merton, 1996). How can these social processes be understood? How are they related to each other? The aim of this study was to further investigate the collective action of bullying and its stigma processes and influences on identities.

\section{Methods}

Grounded theory (GT) methods guided the data collection and analysis (Charmaz, 2006; Glaser, 1978, 1998, 2005; Glaser and Strauss, 1967) based on a constructivist position (Charmaz, 2006). As Mishna and oth- 
ers $(2009$, p. 1222) put it, qualitative research on bullying driven by a GT approach presents an opportunity for developing a deeper understanding of the group processes of bullying and participants' perspectives on peer harassment. It is 'capable of discovering important discourses and nuances' of bullying that might be less visible in largescale studies. The study was based on ethnographic fieldwork in two public schools located in urban neighbourhoods of different socioeconomic statuses, representing both the lower and middle classes, in a medium-sized Swedish city. In total, 96 students (50 boys and 46 girls) from four school classes (two classes in Grade 4 and two classes in Grade 5) participated along with four teachers. The children's age ranged from 10 to 12 years. Informed consent was given by teachers, children and parents.

Observations of peer groups in schools as well as informal conversations and interviews with students and teachers took place, as did observations of anti-bullying team meetings and informal conversations with members of the teams. Field notes and transcripts of audio recordings built up the data. Although short-term or temporary bullying also occurred in the two schools, for this study I explored and analysed six long-term bullying cases in which the victims had been bullied for more than 1 year and were still being bullied during the study (John and Anna in Grade 4; Erica, Tim, Philip and Sandra in Grade 5; all reported names in the study are pseudonyms). The school staff knew three of the cases as ongoing bullying (in these cases, bullying had been going on for a while before the school staff became aware of them; intervention efforts have then been made but the cases were still not resolved). The school staff claimed that one case had been resolved, but I found that the bullying was present during my fieldwork. Two cases were not known to the school staff. In addition to the information of the bullying cases known and reported by the school staff, all bullying cases and its 'bullies' and 'victims' were identified in the ethnographic fieldwork, particularly by the recurrent patterns of reports from children during my informal conversations with them but also by direct observations. Hence, 'bullies' are in this article defined as those who were identified by peers (and in some of the cases also by school staff) as those who repeatedly harassed the victim.

Horton (2011) argues that investigating bullying as an interactive social process requires additional ethnographic studies. I conducted fieldwork, as Lowe (2012, p. 271) puts it, 'to enable the researcher to get as close as possible to the child's perspective of childhood... [including] becoming immersed in the setting by spending time getting to know the children and being involved in their daily activities'. Many childhood researchers and school ethnographers emphasise the value of taking an atypical, less power-oriented adult research role. In line with that, I consciously assumed a 'least-adult role' (Mandell, 1991), avoided 
positions of authority and went through the day-to-day school life with or near the children, including the adoption of a non-judgmental approach. I also told the children at the beginning of the fieldwork that I would not act as a teacher or someone in charge, but more as a guest who wanted to know how school life works, what it is like to be a current student in school, and why teasing and bullying sometimes happens in school. In accordance with the new sociology of childhood, I approached and treated the children as the main informants and competent commentators on their own lives as students in school (Prout, 2002).

Grounded theory methods were used to explore and analyse data. I constantly moved between data collection and analysis during the study by using theoretical sampling, which Glaser and Strauss (1967, p. 45) define as 'the process of data collection for generating theory whereby the analyst jointly collects, codes and analyses his data and then decides what data to collect next and where to find them, in order to develop his theory as it emerges'. During the analysis, coding (creating qualitative codes and categories grounded in data), constant comparison (comparing data with data, data with codes, codes with codes, data with categories and so on), memo writing (writing down ideas about relationships between codes and other theoretical ideas that came to mind during the coding) and memo sorting (comparing and sorting our memos) were the main GT methods in the study.

During the first step of coding (initial/open coding), I tried to remain open to exploring whatever theoretical possibilities I could discern in the data. I developed codes by constantly comparing data with data, data with codes and codes with codes. I was also guided by an array of analytical questions (see Charmaz, 2006; Glaser, 1978), including the following: What is happening in the data? What is going on? What are the main concerns faced by the participants in the action scene? What do the data suggest? What category does this incident indicate? During the next step of coding (focused coding), I used the most significant and frequent initial codes to sift through the large amounts of data. The focused codes I generated in this phase were now more selective and conceptual than the initial codes. Data collection, coding and analysis were guided by these focused codes. In parallel with focused coding (Charmaz, 2006), I began to conduct theoretical coding (Glaser, 1978, 1998, 2005). I explored and analysed how the empirical codes were related to each other and integrated them into a GT by using theoretical codes (e.g. process, identity, normality-deviance and mutual interaction), which refer to underlying logics or patterns embedded in pre-existing theories in many areas. Moreover, during the analysis, pre-existing theoretical concepts from literature, such as social construction, moral disengagement, stigma and labelling were used as 'lenses' and tools that helped me to focus the attention on certain phenomena, aspects and nuances, very much in line with the logic of abduction (Thornberg, 2012). 
Like the theoretical codes that I used, these pre-existing concepts earned their way into the analysis.

\section{Results}

\section{Co-constructing differentness in bullying}

By constantly comparing each case of bullying in the data, the core process of bullying that emerged was the social construction of the targeting child as 'different', 'odd' or 'not like us' with a negative meaning. In bullying, the participants often used dehumanising and oddness-related labels like 'moron', 'ugly', 'nerd', retarded', 'poor man's clothes' disgusting', stupid', stinking' and 'weird', which confirm previous studies showing students' proneness to make victim attributions in bullying (Bibou-Nakou and others, 2012; Frisén and others, 2008; Hamarus and Kaikkonen, 2008; Teräsahjo and Salmivalli, 2003; Thornberg, 2010; Thornberg and Knutsen, 2011; Thornberg and others, 2013; Varjas and others, 2008). For example, one of the victimised children reported, 'They usually tell me that I'm a wimp, and that I'm disgusting because of my rashes on my face' (John, Grade 4). The victims' appearance, personality and behaviour were repeatedly attacked, both in direct verbal bullying and in more indirect forms of bullying such as rumour spreading or just talking about the victims in their absence.

\footnotetext{
Sarah Did you see Erica today, laughing like a stupid moronAnima Like a horse.

Nashad Yeah, with her big horse-teeth! Laughing about stupid things. How funny was that?

Jennifer Not at all.

Sarah But she's laughing [excessively imitating Erica's laugh with a frown].
}

The excerpt above presents a conversation that took place at the playground between four girls in Grade 5. They talked about their classmate, Erica, who was not present. Erica, who has been bullied in the class since first grade, was socially represented here as a 'stupid moron' who oddly laughed at things that were not funny, and was associated with a horse due to her laughing and teeth. The analysis confirmed the use of what Teräsahjo and Salmivalli (2003) identified as 'the odd student repertoire'. When comparing each case of bullying in the data, it became clear to me that bullying in these cases could not be reduced to individual characteristics of the bully and the victim, but indicated a group process that created, manifested and maintained normative orders 
that imposed what was 'normal' and not open to question among the peers (cf. Davies, 2011; Horton, 2011).

\title{
Naturalising and justifying bullying by dehumanising and blaming the victim
}

In accordance with findings from Lahelma (2004) and Teräsahjo and Salmivalli (2003), the co-constructed differentness of the victim was used to explain and justify bullying. For example, Anna in Grade 4 was socially represented by her classmates as a fat girl with odd clothes, and bullying was seen by many peers as a 'natural' consequence of her fat body and odd clothes or, as Frida in her class put it, 'I know it sounds a bit cruel, but she actually has herself to blame. She wouldn't be bullied if she just lost some weight and started to wear normal clothes'. Analyses of many observed peer conversations and interviews with children involved in bullying revealed a recurrent peer discourse of dehumanising and blaming the victim that made bullying 'natural'. When I talked with some boys who bullied Philip, for example, they gave me this explanation:

\author{
Interviewer How come you bully Philip then? \\ Daniel Well, it's because he's different. \\ Interviewer Different? What do you mean? \\ Robin He's not like the rest of us. He plays with younger kids. \\ He doesn't talk much, and when he does, he often says \\ weird things like 'I would like to drive a spaceship', you \\ know. And have you seen his trousers? \\ Interviewer His trousers? \\ Daniel Yeah, he kind of pulls them up to his armpits. \\ Interviewer He does? \\ Fredrik Yeah, it's no wonder that people tease him. \\ Interviewer What do you mean? \\ Fredrik If you are different, you will be teased. \\ (Interview with three boys identified as 'bullies' by their teacher and \\ classmates, in Grade 5)
}

Bandura (1999) has proposed the concept of moral disengagement to refer to a set of socio-cognitive processes through which people can disengage from humane acts and instead behave inhumanely towards other people. He argues that this can happen by different moral disengagement mechanisms such as moral justification (i.e. using worthy ends or moral purposes to sanctify pernicious means), diffusion of responsibility (i.e. assuming that other people who are present in the situation have or will take responsibility), distorting the consequences (i.e. 
minimising, ignoring, or misconstruing the negative or harmful effects of actions), dehumanisation (i.e. stripping the victim of human qualities and equal values) and blaming the victim (i.e. adopting the opinion that the victim deserves the harm or suffering inflicted on him or her). Although previous research has shown how individual bullies and probullies are more prone to display moral disengagement (e.g. Gini, 2006; Gini and others, 2011; Hymel and others, 2005; Menesini and others, 2003; Obermann, 2011; Perren and Gutzwiller-Helfenfinger, 2012), I found several cases showing how moral disengagement was coconstructed among children as a group process, particularly as a peer discourse of dehumanising and blaming the victim.

\begin{tabular}{|c|c|}
\hline Jennifer & There are quite a few who bully her. \\
\hline $\begin{array}{l}\text { Amina } \\
\text { Interviewer }\end{array}$ & $\begin{array}{l}\text { We do too. } \\
\text { How come? }\end{array}$ \\
\hline Amina & $\begin{array}{l}\text { Well, she has to blame herself. Those in the anti- } \\
\text { bullying team say like, 'ooh, what a pity it is for her'- }\end{array}$ \\
\hline Nashad & It's not! \\
\hline Amina & $\begin{array}{l}\text { No, because she is making things this way by herself } \\
\text { kind of believing she can rule. Yeah, well she often } \\
\text { wears weird clothes. }\end{array}$ \\
\hline Jennifer & Not so fashionable. \\
\hline Amina & She is cocky and bossy. \\
\hline Nashad & No one cares about her. \\
\hline Amina & $\begin{array}{l}\text { No, or about what she has to say. We pretend to } \\
\text { be nice to her when a teacher is present, but I prom- } \\
\text { ise you that no one in the class would like to be with } \\
\text { her. }\end{array}$ \\
\hline Interviewer & No one? How come? \\
\hline Nashad & Because everyone thinks she's a jerk. \\
\hline
\end{tabular}

The two excerpts above illustrate how the children collectively dehumanised and blamed the victim in an effort to explain and justify their bullying towards the victim. Blaming the victim was actually often based on the dehumanisation of that person. The meta-message of the bullying to the victim was, 'this is what you are - and we don't like it' linked with 'so this is what you deserve'. 
Both direct and indirect bullying often appeared to function like a selfserving and socially including ritual in which those who participated manifested and maintained their shared 'normality' by (re)producing the victim as different, odd or 'not like us'. Ritual is here understood as group interaction with a shared focus of attention that symbolically confirms the participants' exclusive social belongingness, and produces feelings of group solidarity (Goffman, 1959; Hausmann and others, 2011). Individual interviews with involved children revealed how they socially compared themselves with the targeting child in a way that confirmed their 'normality' as well as their socially included position in the peer group, at the expense of the victim.

$\begin{array}{ll}\text { Kevin } & \text { Sometimes when we are mean to him I think for myself that } \\ & \text { I'm pretty happy I'm not like him. } \\ \text { Interviewer } & \text { How come? } \\ \text { Kevin } & \begin{array}{l}\text { Well, he sucks at football. He's clumsy. He's small. Every- } \\ \text { one thinks he's a dork. To be honest, no one likes to be with } \\ \text { him, just Simon but only because he tries to be nice to him. }\end{array}\end{array}$

(Interview with a boy in Grade 4).

Other regular bullies reported that they thought they and their friends were better than the classmate they bullied (e.g. 'Frida, Johanna and me -we're popular in the class. We're kind of good-looking, and we wear brand clothes. Anna is kind of the opposite, and everyone think she's strange', a girl in Grade 4; 'Others think we're cool. We're good at football ... John is bad in everything', a boy in Grade 4). Thus, bullying (re)constructed belongingness and positive identity for those who cobullied the victim.

\section{Stigma, fear of social contamination and loss of belonging}

By name-calling and teasing, and by rumour spreading and creating a bad reputation, the bullies socially constructed the victims as people who were solely represented as and confined to negative labels. Therefore, the peer discourse of bullying created social expectations that trapped the victims in a self-fulfilling prophecy. They became nothing more than their bullying-induced labels for the classmates. According to Goffman (1963), when a person is stigmatised, others believe he or she is not quite human as a result of a collectively constructed and maintained stigma. This amounts to an ideology that explains the person's inferiority and accounts for the negative things he or she represents, through which others 'effectively, if often unthinkingly, reduce his life chances' (p. 5). The victims' life chances to socialise with peers, develop 
social relations and have friends were indeed severely reduced by the bullying and its discrediting attribution of the victims as deviants.

We don't hang around with her because we have to think about our own reputation (a girl in Grade 4).

We don't want to be with him because everyone thinks he's a nerd. No one likes him. And if we would be with him, people would start think we were nerds too (a boy in Grade 4).

Almost no one in the class would like to be with her... they don't want others to think that they are like her... She's a jerk with ugly clothes and that's why people avoid her (a girl in Grade 5).

If someone would be with her - well then, no one else would like to be with that person either (a girl in Grade 5).

Like the study of Hamarus and Kaikkonen (2008), many of those who did not actively participate in bullying, nevertheless did not want to socialise with the victim. They expressed a fear of social contamination - a fear of becoming a victim by being associated with the actual victim. Søndergaard (2012) uses the concept 'social exclusion anxiety', which is conceptualised as a socially shared affect that 'builds on the social psychological concept of human beings as existentially dependent on social embeddedness' (p. 359). In the context of bullying, the shared 'social exclusion anxiety' blurs the boundaries between bullies and other peers. As reported by former victims of school bullying in Thornberg and others (2013), the victims in this study became involuntarily isolated, rejected or excluded from the most of the social life at school. Loss of belonging, selfdepreciating and identity struggling followed closely upon the sense of becoming socially discredited.

\section{Identity struggling}

The victimised children reported two main concerns. First, there was a struggle for recognition, acceptance and inclusion. Second, there was an identity struggle between being 'normal' associated with value and social acceptance, on one hand, and being 'deviant' and associated with worthlessness and social rejection, on the other. These two concerns were usually intertwined and mutually dependent. 
Sandra Well you know, many think I'm different - that I'm not like them.

Interviewer How do you know that?

Sandra They say so, and I notice that they think that.

Interviewer But are you different?

Sandra I don't know. A little maybe, but I try not to be.

Interviewer What do you mean?

Sandra Well, I try to-, I actually used to think about myself that nothing is wrong with me; I'm just like the others.

Interviewer Why?

Sandra I just do. If I can change myself, if I can prove to them that I'm just like them, they would stop being mean to me. They would think I'm okay and let me be with them.

(Interview with a girl in Grade 5)

Sandra thought that if she could show her classmates that she was just as 'normal' as they were, she would be recognised, accepted and included. Like some of the other victims in the study, she expressed ambivalence towards her own identity. She repeatedly told herself that she was 'normal', but at the same time she was preoccupied with self-changing to be 'normal'. The victims' identities were not set in stone, but were rather a dynamic process, and in the never-ending work of interpretation, many victims seemed to move back and forth between the two types of identity: (a) the 'deviant identity' which refers to a self-image of being different or odd and not fitting in, linked with self-blaming and feelings of worthlessness, and (b) the 'normal identity' which refers to a self-image of being like everyone else linked with feelings of being valuable, and just as good as others.

Some days I really hate myself because of the way I look. I kind of feel sad when I think about it. And I see why they don't want to be with me. Other days I try to think like, 'There's nothing wrong with me! Then I actually feel better (Anna, Grade 4).

How the children accounted for the cause of their being victimised by their peers determined how bullying affected their identity. Being different or a person who does not fit in was a major causal explanation among the victimised children (e.g. 'they bully me because I'm a bit different', John, Grade 4; 'It's because I'm fat', Anna, Grade 4; 'I'm bullied in my class just because I'm not like them', Erica, Grade 5). Being repetitively harassed by peers over time challenged the victimised children's identity and selfesteem. At the same time, self-blaming was built into the victim's understanding of the bullying and the related self-image. 
Anna in Grade 4 reported that she began to be bullied in Grade 2, when some of the boys in her class started to tease and say mean things about her appearance. The bullying spread over the class, and those classmates, who did not tease and call her names, began to ignore her or withdraw from her. Gradually she found herself alone and disliked at school. According to Anna, this affected her self-confidence and view of herself in a very negative way. She said, 'I remember how I began to think bad thoughts about myself, which really made me sad and angry at myself. You know, I was told every day that I was fat, ugly and stupid, so I started to see myself as that... I thought they did this to me because I was fat and ugly, because I was stupid... I know I didn't think that way before all these things started to happen'. Anna indicated that she had incorporated the labelling that took place as part of the bullying, transforming it into an inner process of self-labelling, preceded by and then in interplay with her identity struggling. As a part of that, she also had begun, to some extent, to doubt or question this self-image by recognising that she had assumed her bullies' image of her. For some of the other victimised children, the deviant identity held a much stronger grip on them, resulting in painful and paralysing self-blaming and resignation.

John It doesn't matter what I do because I am who I am. I can't change myself. The teachers can't do anything. Others will always pick on me, because they don't like people who are different.

Interviewer It doesn't matter what you do?

John No, and no one cares because they don't like me [becomes silent and staring at the table].

Interviewer What are you thinking about now?

John It makes me sad. You know, people will always dislike me. (Interview with a boy, Grade 4)

While striving towards normal identity and social acceptance appeared to be associated with efforts to change oneself and to socialise, perceiving the deviant identity as unchangeable and inevitably causing bullying and social rejection appeared to be linked to resignation and a range of escape or avoidance behaviour, such as social withdrawal and avoiding others, as well as trying to be socially invisible in the classroom and other school settings. Even in cases where there was a belief in the possibility of changing oneself, successful self-change was effectively prevented by the social life of the school class.

\section{The victim cycle of expected misfit in the collective action of bullying}

Symbolic interactionism implies that people act together, in what can be termed joint action (Blumer, 1969) or collective action (Becker, 1963). People try to fit their own line of action into the actions of others. Trou- 
bled with a sense of being different and not fitting in (cf. Thornberg and others, 2013), the victimised children strive to become a recognised and accepted member of the peer group by trying to fit in and hence joining the collective action of social life in school. For example, Anna changed her clothing to fit in. John tried to play football with the majority of the boys in the class during the breaks. Erica tried to hang about with some of the other girls and to participate in their everyday conversations. The problem was that the victims already played an involuntary role in an ongoing pattern of collective action. The peers were already engaged in the fitting of lines of action to each other into the joint or collective action of bullying when the victimised classmate was physically present or present as a topic in their conversations.

According to Goffman (1959), in everyday life people engage in performances to present themselves to others, in which they work collectively or as a team to express the characteristics of the actual social situation and with no acceptance of participants communicating out of character (i.e. expressing or communicating sentiments that are in conflict or at odds with the requirements of a performance). The analysis of the data indicated how the victimised children were trapped in their roles as a result of the repeated interaction pattern of everyday bullying. Not fitting in was actually a kind of unwilling fitting of lines of action into the actions of others. In the collective action or performance of bullying, the bullied children were forced to play the role of the victim, which also was the role of not fitting in. If victims tried to change something about themselves, it was never good enough (e.g. 'It doesn't matter if he wear his new Converse shoes, he's still a nerd', a boy in Grade 5). The performance of bullying did not accept having the victims play out of character, but persisted in the collective definition of their differentness.

\section{Conclusion}

In line with a constructivist position of GT, I do not claim to offer an exact picture but rather an interpretative portrayal of the phenomenon studied (Charmaz, 2006). This portrayal indicates the need of considering and investigating bullying as a collective action, including its stigma processes and co-constructions of meanings, social roles and identities. As Horton (2011, p. 274) puts it, 'rather than categorising large numbers of school students as deviant, aggressive or evil-minded, it may be more useful to consider the social processes in which they are involved when bullying occurs'. The analysis of the long-term bullying cases revealed a complex interactional patterns creating stigma processes in which the bullying was considered the natural thing to do, and was justified by dehumanising and blaming the victim. At the same time, it functioned as a self-serving and socially inclusive ritual for the bullies, in which they co-constructed the 
'normal us'. The findings highlight the importance of working with peer cultures, social norms and collective processes to counteract and reduce bullying. Only focusing on 'bullies' and 'victims' will not be enough. Thus, anti-bullying policies and practices have to address the social processes of bullying and the co-construction of moral disengagement among the children. The schools have to help the children fulfil their needs of positive identities, social acceptance and belongingness based on constructive, inclusive and caring social interactions and co-constructions of meanings, and not on bullying and its underlying discourse of homogeneity and disapproval of differentness.

\section{References}

Atkinson P, Housley W. 2003. Interactionism. Sage: London.

Bandura A. 1999. Moral disengagement in the perpetration of inhumanities. Personality and Social Psychology Review 3:193 - 209.

Becker HS. 1963. Outsiders: Studies in the Sociology of Deviance. The Free Press of Glencoe: New York.

Bibou-Nakou I, Tsiantis J, Assimopoulos H, Chatzilambou P, Giannakopoulou D. 2012.

School factors related to bullying: a qualitative study or early adolescent students. Social Psychology of Education 22: 125 - 145.

Blumer H. 1969. Symbolic Interactionism. University of California Press: Berkeley, CA. Cadigan RJ. 2002. Scrubs: An Ethnographic Study of Peer Culture and Harassment among Sixth Graders in an Urban Middle School. University of California: Los Angeles.

Charmaz K. 2006. Constructing Grounded Theory. Sage: London.

Charon JM. 2007. Symbolic Interactionism: An Introduction, an Interpretation, an Integration, 9th edn. New Jersey: Prentice-Hall.

Corsaro WA. 2005. The Sociology of Childhood, 2nd edn. Pine Forge Press: Thousand Oaks.

Davies B. 2011. Bullies as guardians of the moral order: re-thinking the origins of bullying in schools. Children \& Society 25: $278-286$.

Dixon R, Smith P, Jenks C. 2004. Bullying and difference: a case study of peer group dynamics in one school. Journal of School Violence 3:41 - 58.

Evaldsson A-C, Svahn J. 2012. School bullying and the micro-politics of girls' gossip disputes. In Disputes in Everyday Life. Danby S Theobald M (eds.). Bingley: Emerald; 297-323.

Evans C, Eder D. 1993. 'No exit' : processes of social isolation in the middle school. Journal of Contemporary Ethnography 22: 139 - 170.

Frisén A, Holmqvist K, Oscarsson D. 2008. 13-year-olds' perception of bullying: definitions, reasons for victimisation and experience of adults' response. Educational Studies 34: $105-117$.

Gini G. 2006. Social cognition and moral cognition in bullying: what' s wrong? Aggressive Behavior 32: 528 - 539.

Gini G, Pozzoli T, Hauser M. 2011. Bullies have enhanced moral competence to judge relative to victims, but lack moral compassion. Personality and Individual Differences 50: $603-608$.

Glaser BG. 1978. Theoretical Sensitivity. Sociology Press: Mill Valley, CA.

Glaser BG. 1998. Doing Grounded Theory: Issues and Discussions. Sociology Press: Mill Valley, CA. 
Glaser BG. 2005. The grounded Theory Perspective III: Theoretical Coding. Sociology Press: Mill Valley, CA.

Glaser BG, Strauss AL. 1967. The Discovery of Grounded Theory. Aldine: New York. Goffman E. 1959. The Presentation of Self in Everyday Life. Doubleday: Garden City, NY. Goffman E. 1963. Stigma. Simon \& Schuster: New York.

Hamarus P, Kaikkonen P. 2008. School bullying as a creator of pupil pressure. Educational Research 50: 333 - 345.

Hausmann C, Jonason A, Summers-Effler E. 2011. Interaction ritual theory and structural symbolic interactionism. Symbolic Interaction 34:319 - 329.

Horton P. 2011. School bullying and social and moral orders. Children \& Society 25: 268 277.

Hymel S, Rocke-Henderson N, Bonanno RA. 2005. Moral disengagement: a framework for understand- ing bullying among adolescents. Special Issue of Journal of Social Sciences 8: $1-11$.

Kinney DA. 1993. From nerds to normals: the recovery of identity among adolescents from middle to high school. Sociology of Education 66: 21-40.

Kless SJ. 1992. The attainment of peer status: gender and power relationships in the elementary school. Sociological Studies of Child Development 5: 115-148.

Lahelma E. 2004. Tolerance and understanding? Students and teachers reflect on differences at school. Educational Research and Evaluation 10: 3-19.

Lowe RJ. 2012. Children deconstructing childhood. Children \& Society 26: 269-279.

Mandell N. 1991. The least-adult role in studying children. In Studying the Social Worlds of Children: Sociological Readings. Waksler FC (ed.). Falmer Press: London; 38-59.

Menesini E, Sanchez V, Fonzi A, Ortega R, Costabile A, Feudo GL. 2003. Moral emotions and bullying: a cross-national comparison of differences between bullies, victims and outsiders. Aggressive Behavior 29:515-530.

Merton DE. 1996. Visibility and vulnerability: responses to rejection by nonaggressive junior high school boys. Journal of Early Adolescence 16: 5-26.

Mishna F, Saini M, Solomon S. 2009. Ongoing and online: Children and youth's perceptions of cyberbullying. Children and Youth Services Review 31:1222-1228.

Obermann M-L. 2011. Moral disengagement in self-reported and peer-nominated school bullying. Aggressive Behavior 37: 133-144.

Perren S, Gutzwiller-Helfenfinger E. 2012. Cyberbullying and traditional bullying in adolescence: different roles of moral disengagement, moral emotions, and moral values. European Journal of Developmental Psychology 9: 195-209.

Phelan JO, Link BG. 1999. The labelling theory of mental disorder (1): the role of social contingencies in the application of psychiatric labels. In A Handbook for the Study of Mental Health: Social Contexts, Theories, and Systems. Horwitz AV, Scheid TL (eds.). Cambridge University Press: Cambridge; 139-149.

Prout A. 2002. Researching children as social actors: an introduction to the Children 5-16 Programme. Children \& Society 16: 67-76.

Prout A, James A. 1997. A new paradigm for the sociology of childhood? Provenance, promise and problems. In Constructing and Reconstructing Childhood, 2nd edn. James A, Prout A (eds). The Falmer Press: London; 7-33.

Salmivalli C. 2010. Bullying and the peer group: a review. Aggression and Violent Behavior 15: 112-120.

Søndergaard D-M. 2012. Bullying and social exclusion anxiety in schools. British Journal of Sociology of Education 33:355-372.

Teräsahjo T, Salmivalli C. 2003. 'She is not actually bullied': the discourse of harassment in student groups. Aggressive Behavior 29: 134-154.

Thornberg R. 2010. Schoolchildren's social representations on bullying causes. 
Psychology in the Schools 47: 311-327.

Thornberg R. 2012. Informed grounded theory. Scandinavian Journal of Educational Research 56: 243- 259.

Thornberg R, Knutsen S. 2011. Teenagers' explanations of bullying. Child \& Youth Care Forum 40: 177-192.

Thornberg R, Halldin K, Petersson A, Bolmsjö N. 2013. Victimising of school bullying: a grounded theory. Research Papers in Education 28: 309-329.

Varjas K, Meyers J, Bellmoff L, Lopp E, Birckbichler L, Marshall M. 2008.

Missing voices: fourth through eighth grade urban students' perceptions of

bullying. Journal of School Violence 7: 97-118.

Wyness M. 2006. Childhood and Society: An Introduction to the Sociology of

Childhood. Palgrave MacMillan: New York. 